\title{
TÉCNICA, CIÊNCIA E DIREITO DA SUSTENTABILIDADE ${ }^{1}$
}

TECHNIQUES, SCIENCE AND LAW IN SUSTAINABILITY

TÉCNICA, CIENCIA Y DERECHO DE LA SOSTENIBILIDAD

\section{Rubens Losada de Menezes²}

Resumo: A técnica ou tecnologia em constante evolução sóciohistórica progrediu de modo entrelaçado às ciências naturais, que por sua vez aportaram ao homem meios potencialmente aptos a prognosticar os eventos ambientais presentes e futuros. Igual fato ocorreu com o Direito, particularmente com a especialidade ambiental, que ainda hoje se apoia marcadamente no influxo técnico-ecológico propiciado pelas ciências naturais para solucionar as questões vinculadas à sustentabilidade ecológica (ambiental), social e econômica. Logo, o presente artigo, pelo método indutivo, ante à emergente ciência da sustentabilidade, apontará pela necessidade dos pesquisadores, sobretudo da ciência jurídica, a se esforçarem do ponto de vista epistemológico para atingirem uma adequada integração das ciências naturais, sociais e humanidades

1 As reflexões apresentadas no artigo são extraídas da tese doutoral titulada "La reintegración de la técnica en el derecho ambiental para la evaluación y vigilancia de la sostenibilidad", elaborada junto ao Programa de Doutorado em Direito Ambiental da Universidad de Alicante, dirigida pelo eminente Gabriel Real Ferrer, aprovada pela notável banca examinadora presidida por Michel Prieur/Université de Limoges e composta por: Juan González Márquez/Universidad Autónoma Metropolitana; Paulo Márcio Cruz/Universidade do Vale do Itajaí; Josep Ochoa Monzó/Universidad de Alicante e Maurizio Oliviero/I'Università degli Studi di Perugia.

2 Doutor em Direito Ambiental pela Universidad de Alicante. Diploma de Estudios Avanzados em Direito pela Universidad de Burgos. Consultor jurídico em sustentabilidade. E-mail: rubenslosada@gmail.com. 
no processo de compreensão das interações socioecológicas. Para tanto, demanda-se expandir a funcionalidade dos métodos e técnicas sociais dentro da normativa ambiental e, especialmente, estimular a participação social nos processos de tomada de decisão, assim como nos instrumentos de gestão ambiental.

Palavras-chave: Técnica. Ciências Naturais. Ciências Sociais. Direito Ambiental. Ciência e Direito da Sustentabilidade.

Abstract: Socio-historical techniques and technology are constantly evolving, fuelled by the interface with the natural sciences, which in turn, enables us to interpret and predict the meaning of present and future environmental events. The same thing is happening with the law, particularly with environmental expertise, influenced largely by the natural sciences to address issues related to ecological (environmental), social, and economic sustainability. Thus, at present, inductive reasoning on the emerging science of sustainability points to the need for researchers, especially in legal science, to make efforts, from an epistemological perspective, to achieve a proper integration of the natural sciences, social and humanities, as part of the process of understanding socio-ecological interactions. Therefore, there is a need to expand the functionality of social methods and techniques used when dealing with environmental regulations, and in particular, we need to encourage social participation in the decision making processes, as well as in environmental management tools.

Keywords: Practices. Natural Sciences. Social Sciences. Environmental Law. Sciences and Laws of Sustainability

Resumen: La técnica o tecnología en constante evolución socio histórica progresó de modo entrelazado a las ciencias naturales, que a su vez aportaron al hombre medios potencialmente aptos a pronosticar los eventos ambientales presentes y futuros. El mismo hecho ocurrió con el Derecho, particularmente con la especialidad ambiental, que aún hoy se apoya marcadamente en el influjo técnico-ecológico propiciado por las ciencias naturales para solucionar las cuestiones vinculadas a la sostenibilidad ecológica (am- 
biental), social y económica. De este modo, el presente artículo, a través del método inductivo y ante la emergente ciencia de la sostenibilidad, señalará la necesidad de que los investigadores, sobre todo los de la ciencia jurídica, se esfuercen desde el punto de vista epistemológico para alcanzar una adecuada integración de las ciencias naturales, sociales y humanas en el proceso de comprensión de las interacciones socio ecológicas. Para ello se demanda expandir la funcionalidad de los métodos y técnicas sociales dentro de la normativa ambiental y especialmente estimular la participación social en los procesos de toma de decisión, así como en los instrumentos de gestión ambiental.

Palabras clave: Técnica. Ciencias Naturales. Ciencias Sociales. Derecho Ambiental. Ciencia y Derecho de la Sostenibilidad.

\section{INTRODUÇÃO}

ciência, a partir do período moderno, se diferencia notavelmente de
tempos anteriores, pois promoveu eventos notáveis devido à sua
aplicabilidade prática. Desde então, a racionalidade científica, em constante evolução sócio-histórica, promove um avanço contínuo de técnicas potencialmente adequadas a controlar e prognosticar os efeitos e as interações ambientais sucedidas no entorno das sociedades contemporâneas.

Portanto, antes de avizinhar ao que se pode considerar como técnica, e especificamente ao seu papel na configuração das características físico-naturais do entorno e dos comportamentos socioeconômicos contemporâneos que se apresentam, é fundamental aos operadores do Direito conhecer um pouco da recalcitrante andadura científica, com conotação filosófica e sócio-histórica, a fim de conhecer seus êxitos e brechas básicas quando em conexão com os sistemas jurídicos vigentes e, em especial, quando em contato com o tradicional Direito Ambiental, que cumpre, desde a ciência jurídica, remodelar-se ante os pilares científicos - ecológico ${ }^{3}$, social e econômico - que impõem o debatido paradigma 3 Parece preferível usar o termo ecológico no lugar de ambiental para qualificar a terceira dimensão da sustentabilidade, já que ambiental parece transcender e englobar todas as demais facetas dessa concepção. Porém, na bibliografia dedicada à sustentabilidade, em- 
da sustentabilidade ${ }^{4}$.

\section{MODERNIDADE TÉCNICA}

A ciência, como se concebe atualmente, foi um produto relativamente tardio no desenvolvimento geral da civilização. Antes do período moderno, não se pode dizer que houve prática científica diferente da levada a cabo por filósofos e artesãos. Sendo assim, admite-se que a ciência teve origem em duas fontes primárias. Primeiro, na tradição técnica dos artífices, em que as habilidades foram aprimoradas de modo intergeracional; já a segunda fonte amparou-se na tradição filosófica, meio por qual os pensamentos se transmitiram e aumentaram os ideários humanos 5 .

\section{Sabe-se que a revolução científica durante o século XVII promoveu} mudanças extraordinárias na maneira pela qual a cultura ocidental examinava os fatos desencadeados no mundo, e os métodos utilizados para averiguar a natureza durante esse período são considerados tão importantes que devem ser considerados como paradigmáticos. Portanto o sucedido nesse período foi nada prega-se, de forma geral, ambos termos como se fossem sinônimos (Vide: GÓMEZ OREA, Domingo; GÓMEZ VILLARINO, Mauricio. Consultoría e ingeniería ambiental: planes, programas, proyectos, estudios, instrumentos de control ambiental, dirección y ejecución ambiental de obra, gestión ambiental de actividades. Madrid: Mundi-Prensa, 2007. p.46). Portanto, a efeitos metodológicos, ao longo do texto, ainda que a maior parte da literatura e dos documentos do Programa das Nações Unidas para o Meio Ambiente (PNUMA) apontem o "ambiental" (proteção ambiental) como "ecológico", far-se-á distinção entre os termos: ecológico, deve ser entendido como os distintos componentes e processos físico-naturais, abióticos e bióticos, que se desenvolvem no entorno; enquanto ambiental, envolve e se expande aos demais pilares, econômico e social (ou, simplesmente, socioeconômico) do que se planifica à sustentabilidade.

4 Sobre a aplicabilidade de um paradigma à ciência, Thomas Kuhn esclarece que: "(...). En su uso establecido, un paradigma es un modelo o patrón aceptado y este aspecto de su significado me ha permitido apropiarme la palabra 'paradigma', a falta de otro término mejor. (...) Por otra parte, en una ciencia, un paradigma es raramente un objeto para renovación. En lugar de ello, tal y como una decisión judicial aceptada en el derecho común, es un objeto para mayor articulación y especificación, en condiciones nuevas o más rigurosas. Para comprender cómo puede suceder esto, debemos reconocer lo muy limitado que puede ser un paradigma en alcance y precisión en el momento de su primera aparición. Los paradigmas obtienen su status como tales, debido a que tienen más éxitos que sus competidores para resolver unos cuantos problemas que el grupo de profesionales ha llegado a reconocer como agudos. Sin embargo, el tener más éxito no quiere decir que tenga un éxito completo en la resolución de un problema determinado o que dé resultados suficientemente satisfactorios con un número considerable de problemas." In: KUHN, Thomas S. La Estructura de las revoluciones científicas. México. Fondo de Cultura Económica, 1987. p.51 e 52. MASON, Stephen F. Historia de las ciencias. Barcelona: Zeus, 1966. p. 11 e 12. 
menos que a gênese da ciência moderna; logo, se o enfoque histórico é adequado, os grandes nomes vinculados a essa eclosão da racionalidade, como Copérnico, Descartes, Galileu e Newton, têm o legítimo direito de serem indicados como os genitores da modernidade. Tais científicos têm patenteados não só grandes inventos e teorias científicas, também foram os responsáveis por preconizarem o método científico, que veio proporcionar uma via de escadrinhamento da natureza e da realidade humana ${ }^{6}$.

Desde então, a atividade científica trata de decifrar o mundo, e a faz de forma progressiva, em oposição declarada à irracionalidade das aproximações teológicas e metafísicas, seu marco é a racionalidade, o instrumento, o método científico; esse que, apreende-se, geralmente, como um processo que tende a explicar os fatos e pretende fazê-lo em um marco numérico ${ }^{7}$. Segundo G. Tyler Miller, os métodos científicos são os meios pelos quais os científicos reúnem dados, formulam e provam as teorias científicas. Ou seja, um método científico é um conjunto de interpelações, sem regras particulares para contestá-las. Quanto à finalidade preditiva da ciência, destaca que é um intento de entender o funcionamento da natureza para depois utilizar esse conhecimento para fazer predições acerca do que sucederá. Para tanto, o investigador reúne dados científicos, por meio de observações e medições, porém se deve destacar que coletar dados não é o propósito basilar da atividade científica, visto que dados são apenas degraus para se chegar a uma teoria científica, que esquematizará o que ocorrerá na natureza.

Uma vez formulada uma teoria científica, os expertos da ciência tratam de explicar como ou por que os fatos sucedem de certa forma. Para isso, formulam uma hipótese científica, que esclareça essa teoria ou determinado fato científico. Conseguinte, põem à prova referida hipótese, por meio de observações e medições. Caso muitos experimentos efetuados por distintos científicos a sustentem, a hipótese chega a ser uma teoria; isto é, uma teoria científica é uma hipótese bem acreditada e aceita pela comunidade científica. Por outro lado, tal acreditação não pode fomentar a errônea percepção de que a ciência possa produzir provas ou verdades absolutas, pois os científicos perseguem apenas o 6 BOWLER, Peter J.; MORUS, Iwan Rhys. Panorama general de la ciencia moderna. Traducción de Joan Soler. Barcelona: Critica. 2007. p.31.

7 SANMARTÍN, José. Tecnología y futuro humano. Barcelona: Anthropos, 1990. p.28. 
que é oportuno à teoria ou à lei, para descrever, explicar e predizer o que passa na natureza. Em resumo, a ciência comprova e aceita o que funciona, no entanto a teoria científica, já que baseada em fontes estatísticas, não em certezas, pode ser modificada a qualquer momento, basta que se aportem explicações mais adequadas sobre o complexo tramado de interações que ocorrem na naturezå

Cabe lembrar que a investigação científica não se limita ao estudo dos processos naturais, ou seja, à observação de acontecimentos que produzem de modo espontâneo no ambiente. Entretanto é inquestionável que a ciência se baseia em boa medida em referida atividade observacional, para logo experimentar, instrumental e artificialmente e analisar os efeitos gerados no mundo natural. Em um contexto em que o método científico, experimental, é quase sinônimo de prática científica, há de esclarecer que o conceito de experimento engloba um amplo leque de labores científicos, que não se pode definir com exatidão, porém, considerado como método metacientífico geral para examinar a natureza e promover descobertas, comumente detém certos atributos: empirismo, mediante a percepção humana direta ou por meio de instrumentos; artificialidade, os acontecimentos devem ser provocados, em geral, em condições tecnicamente controláveis, visto que frequentemente são artificiais e antinaturais; intencionalidade; propósito racional; e originalidade, uma informação científica nova?

Dentro dessa concepção metodológica e experimental do conhecimento científico, em que insurge a técnica como produto científico e, por sua vez, como instrumento de modificação ambiental, são importantes as definições de José Sanmartín quanto a seu conceito e melhor enquadre teórico. Destaca que a ciência é teoria, construída por meio do método científico, portanto objetiva e neutral. A teoria oferta explicações racionais, isto é, aclarações causais que, na medida do possível, fazem uso de quantidades no lugar de qualidades. Umas

8 MILLER, G. Tyler. Ecología y medio ambiente: introducción a la ciencia ambiental, el desarrollo sustentable y la conciencia de conservación del planeta tierra. Traducción Irma de León Rodríguez y Virgilio González Velázquez. México: Grupo Editorial Iberoamérica, 1994. p.58 e 59.

9 ZIMAN, John. Introducción al estudio de las ciencias: los aspectos filosóficos y sociales de la ciencia y la tecnología. Traducción Jordi Bertrán Ferrer. Barcelona: Ariel, 1986. p.34 e 35. 
teorias suprem outras, quando estas últimas, expostas à crítica ou à correção de falhas pela sociedade científica, exibem problemas que outras solucionam, de tal forma que se gera constante debate científico para substituir teorias com menor informação verdadeira por outras com maior conteúdo informativo verdadeiro.

As teorias, finalmente, podem ou não se aplicar, ofertando tecnologias, que são entendidas como as técnicas que incidem sobre os processos causais, elucidados pelas teorias em questão. Enfatiza que antes de ter tecnologias deve haver teorias, mas desde logo, a ciência, identificada com a teoria, não tem nada que ver, em princípio, com a técnica ou a tecnologia, já que antes de contar com a tecnologia se devem possuir teorias, mas, por outro lado, pode-se ter teorias e não contar com tecnologias ${ }^{10}$. Segundo Miguel Ángel Quintanilla, dentro da terminologia científica, os termos técnica e tecnologia são imprecisos, pois se costuma utilizá-los como sinônimos. Na literatura especializada, tende-se a reservar o termo técnica às técnicas artesanais précientíficas; e tecnologia às técnicas industriais vinculadas ao conhecimento científico. Porém os filósofos, os historiadores e os sociólogos da técnica se referem com um ou outro termo tanto aos artefatos que são produto de uma técnica ou tecnologia, como aos processos e aos sistemas de ação que dão lugar a esses produtos e, sobretudo, os conhecimentos sistematizados, no caso da tecnologia; ou não sistematizados, no caso de muitas técnicas artesanais, em que se baseiam as realizações técnicas.

Porém enfatiza que o conceito de técnica se usa muito frequentemente em sentido amplo, de forma que inclui tanto atividades produtivas, artesanais ou industriais, como atividades artísticas ou estritamente intelectuais. ${ }^{11} \mathrm{Em}$ linhas análogas, Ramón Queraltó enfatiza que a maior parte da literatura científica e filosófica entende por tecnologia a técnica derivada diretamente da ciência moderna, isto é, a inspirada especificamente nela como uma de suas consequências históricas. Portanto o termo técnica ostentaria um significado generalizante, pois acompanharia a civilização humana desde seu começo, como uma via de mediação antropológica frente ao mundo, e a tecnologia seria uma 10 SANMARTÍN, José. Tecnología y futuro humano. p.29 e 30.

11 QUINTANILLA, Miguel Ángel. Tecnología: un enfoque filosófico. Madrid: Fundesco, 1989. p.33. 
classe específica de técnica científica, que é a que domina a partir do surgimento da ciência moderna ${ }^{12}$.

Como regra geral, ao logo do texto, igual a outros autores, não se distinguirão os termos técnica e tecnologia, pois não haverá de serimportante para o desenvolvimento das matizações jurídicas que se desenvolverá. Além disso, apregoar essa distinção haveria de complicar a exposição, que por si só é árdua desde a perspectiva jurídica. Portanto a técnica ou tecnologia aqui referendadas são aquelas vinculadas às teorias científicas modernas e contemporâneas, de caráter experimental e artificial, e que apresentam, com o progresso das ciências da natureza, larga tradição e profusão, seja como meio de proporcionar uma racional modificação ambiental e, simultaneamente, como instrumento para identificar, avaliar e controlar o funcionamento dos fatores ambientais associados (solo, recursos hídricos, atmosfera, paisagem, etc.), sejam em circunstâncias naturais ou antrópicas.

\section{TÉCNICA, INDÚSTRIA E CIÊNCIAS NATURAIS}

A capacidade hermenêutica das ciências naturais, em especial da física, incrementou-se progressivamente a princípios do séc. $X X$, sendo muitos os que as viam como uma verdadeira força motriz na instauração e na manutenção da sociedade moderna. ${ }^{13}$ Segundo essa concepção, conhecida pelos estudiosos como determinismo tecnológico, as mudanças promovidas pela tecnologia influem nas sociedades e em seus processos mais que qualquer outro fator ${ }^{14}$. Dessa forma, devido ao fato de que a era moderna, como período histórico, origina com a ciência e a técnica, que mostram hoje estrondosa capacidade de proliferação, pode-se dizer que essa modernidade é tão submergida na tecnicidade, que pode ser inclusive denominada como modernidade técnica ${ }^{15}$.

12 QUERALTÓ, Ramón. Razón científica y razón técnica en el fin de la modernidad. Anuario Filosófico, Navarra, v.27, n.2, p.683-697.1994. p.684.

13 CUTCLIFFE, Stephen H. Ideas, máquinas y valores: Los estudios de Ciencia, Tecnología y Sociedad. Traducción Isabel Chacón Chacón. Barcelona: Anthropos; México: Universidad Nacional Autónoma de México, 2003. p.26.

14 SMITH, Merrit Roe. El determinismo tecnológico en la cultura de Estados Unidos. In: Merrit Roe Smith; Leo Marx (Eds.). Historia y determinismo tecnológico. Traducción Esther Rabasco y Luis Toharia. Madrid: Alianza, 1996. p.19-51. p.19.

15 BRÜSEKE, Franz Josef. A Modernidade Técnica. Revista Brasileira de Ciências Sociais, São Paulo, v.17, n.49, p.135-144, junho, 2002. p.135. 
O caráter finalista da ciência e sua definição como meio apto a alcançar fins definidos pelo homem é algo inquestionável e que surgiu no velho mundo. Portanto, somente no contexto europeu notou-se uma larga fase histórica, que começa ao final da Idade Média e se estende até as vésperas da Revolução Industrial, uma maneira específica de pensar, a qual se chama de científica. $\mathrm{Na}$ sequência histórica, ciência, técnica e capitalismo, essa aliança faz com que o industrialismo ecloda, e não deixa dúvidas de que os tempos vindouros se distinguiriam de forma radical de tempos anteriores ${ }^{16}$. Em outras palavras, a modernidade aspirou levar a tecnologia a todos os âmbitos, em particular, desde o século XVIII, buscou aplicá-la sistematicamente ao setor industrial ${ }^{17}$.

Desde o momento em que a ciência, com sua característica de fusão de teoria e prática, se converteu em tecnociência, ela propiciou ao homem a potencialidade de alterar massivamente a realidade em prazos muito curtos. Diz-se tecnociência, porque o que está em questão não é simples técnica de base científica, mas sim algo que vai além: as novas realizações da ciência estão cada vez mais direcionadas à manipulação técnica da realidade, operação essa que se efetua de modo entrelaçado com as ciências naturais ${ }^{18}$. Tal como destaca Hebert Marcuse, as ciências naturais se desenvolveram graças a um influxo tecnológico que projeta a natureza como um instrumento potencial, de controle e organização, e a apreensão da natureza como "instrumento hipotético" demanda o desenvolvimento de toda uma organização técnica particular ${ }^{19}$. Conforme Jürgen Habermas, a física moderna, em complementaridade com as ciências naturais, foi objeto de leitura filosófica em que se interpretam a natureza e a sociedade, e induziu à construção da imagem mecanicista do mundo. A ciência assumiu nesse contexto uma função

16 BRÜSEKE, Franz Josef. Riesgo y contigencia. In: VARELLA, Marcelo Dias (Org.). Derecho, sociedad y riesgo. La sociedad contemporánea vista a partir de la idea de riesgo: Rede Latinoamericana y europea sobre gobierno de los riesgos. Brasília: UniCEUB, UNITAR, 2007. p.87-120. p.114.

17 SANMARTÍN, José; ORTÍ, Ángel. Evaluación de tecnologías. ¿Qué es? ¿En qué contribuye a clarificar las relaciones entre tecnología y sociedad? ¿Cuáles son sus limitaciones? ¿Hay alternativas? In: SANMARTÍN, José et al. (Eds.). Estudios sobre sociedad y tecnología. Barcelona: Anthropos; Leioa (Vizcaya): Universidad del País Vasco, 1992. p.42-66. p.43.

18 SEMPERE, Joaquim; RIECHMANN, Jorge. Sociología y medio ambiente. Madrid: Editorial Síntesis. 2000. p.311.

19 MARCUSE, Herbert. El hombre unidimensional: ensayo sobre la ideología de la sociedad industrial avanzada. Traducción Antonio Elorza. Barcelona: Ariel, 1984. p.180. 
inconfundível, pois, distinta das ciências filosóficas de velho cunho, desenvolveu-se em um marco metodológico de referência, que reflete a possível disposição técnica do conhecimento. Se bem, em geral, as oportunidades de aplicação só se deram posteriormente, e não se registra uma interdependência entre ciência e técnica até fins do século XIX; até então, tem-se que a ciência não contribuiu para aceleração do desenvolvimento técnico, seu aporte a esse processo foi mais indireto ${ }^{20}$.

A finalidade das ciências naturais é ampliar e melhorar o conhecimento sobre o funcionamento do entorno natural, mediante exigentes provas experimentais e observacionais. Ainda que não haja um método universal, que esteja acima da realidade dos fatos, e sempre exista a possibilidade de fracasso, o objetivo científico normalmente se consegue, independente da intencionalidade subjetiva do experto. Isto é, apesar do caráter social de toda prática científica, desenvolveram-se na prática alguns métodos e táticas para elaborar conhecimento objetivo acerca do entorno natural, sem embargo, os mesmos deveriam ser mais acautelados e aprimorados ${ }^{21}$. Ou seja, na vertente técnica stricto sensu, modificadora das estruturas ecológicas, a ciência, especialmente traduzida nas inovações tecnológicas geradas pelas ciências naturais, foi o principal ingrediente para eclosão do industrialismo pós-moderno e base fundamental para o início de uma considerável modificação da biosfera, que, por meio de técnicas cada dia mais aprimoradas, chegou aos dias de hoje com larga dose de complexidade ecológica, mas igualmente, socioeconômica.

Deve-se destacar que as ciências naturais, em seus inúmeros compartimentos disciplinares, constituem a sistematização e a formalização de teorias científicas acerca dos fatores ecológicos ou naturais do entorno humano e das demais espécies. Essa tarefa é facilitada devido às similitudes e às interconexões que são evidenciadas na realidade metodológica e experimental, que propiciam aos expertos de referida categoria a possibilidade de intercambiarem dados e informações para a construção do conhecimento científico. Portanto se tem que as ciências naturais são um conjunto de conhecimentos que se acham acoplados

20 HABERMAS, Jürgen. Ciencia y técnica como "ideología". Traducción Manuel Jiménez Redondo y Manuel Garrido. 5. ed. Madrid: Tecnos, 2007. p.80.

21 CHALMERS, Alan F. La ciencia y cómo se elabora. Traducción Eulalia Pérez Sedeño. Madrid: Siglo Veintiuno de España, 1992. p.148. 
por razões de correspondência e similitude de objetos científicos, que em muitas ocasiões coincidem na investigação do ambiente em seus elementos bióticos e abióticos; tudo isso de forma a permitir gerar dados, teorias e técnicas que atuem sobre o mesmo de forma artificial e dentro de padrões científicos seguros. Em suma, com a experimentação e a consequente tecnificação, as ciências naturais se destacam por ser profundamente associadas aos setores industriais e, quando alocadas aos canais normativos para a organização social, presumem-se como meio capaz de intervir e controlar tecnicamente os fatores ambientais e seus distúrbios no seio das sociedades contemporâneas.

\section{DIREITO AMBIENTAL E INFLUXO TÉCNICO-ECOLÓGICO.}

A ciência natural se transformou cada vez mais em produtora e produto de uma dinâmica tecnocientífica, que se converte cada vez mais em produtora e produto da dinâmica socio-histórica, como bem assinala Edgar Morin. Ao disseminar na sociedade, na economia e no estado, a ciência foi objeto de industrialização e tecnoburocratização. Conseguinte, o conhecimento científico determina cada vez mais o desenvolvimento social, econômico e técnico, mas resulta cada vez mais incorporada política, jurídica, social, econômica e tecnicamente, determinando o que é certo e seguro na civilização técnica ${ }^{22}$. Em outras palavras, a predição e o controle técnico se mostram tentadores aos Poderes públicos, pois os aparatos e as técnicas estão pensados para uns desígnios objetivos. Por sua própria natureza, os meios técnicos são meros instrumentos sujeitos à vontade de quem quer que os utilizem, por isso a atividade política sempre teve grande interesse na combinação casual segurança e controle ofertada pela lógica técnica. Nesse sentido, deve-se destacar que muitas formas históricas da arte de governar e parte das concepções utópicas se baseiam tacitamente em um modelo técnico, pois quando as condições do mundo político-institucional parecem incertas e difíceis de administrar, os sistemas técnicos se mostram como uma sugestível solução ${ }^{23}$.

22 MORIN, Edgar. El método. 6. ed. Madrid: Cátedra, 2001. p.62 e 63.

23 WINNER, Langdon. Tecnología autónoma: la técnica incontrolada como objeto del pensamiento político. Traducción Ramón Font Segura y Alberto Cardín Garay. Barcelona: Gustavo Gili, 1979. p.35. 
A crise sanitária e ambiental promoveu transformações institucionais próprias da ciência e da técnica, tais como os comitês de ética, ministérios especializados, agências sanitárias, ambientais, etc. Ao vislumbrar tais evoluções, aparentemente aleatórias, e contrastá-las com o Direito, denota-se que tais avanços institucionais concernem, de fato, aos Poderes executivo, legislativo e judicial ${ }^{24}$. Portanto, com o avanço da tecnificação, o Poder público foi impulsionado a ampliar seu papel dirigido à preservação e à conservação ambiental e, para tanto, desenvolveu extensa legislação ambiental e se estruturou mediante a criação de descentralizações aptas a assumir a gerência dos conflitos ambientais. Ou seja, foi dado o estalo inicial da regulação normativa do meio ambiente, muito especialmente por meio de sistemas jurídicos de indução técnico-ecológica. Sem embargo, essa abordagem tecnicista para a avaliação, gestão e limitação dos híbridos riscos e impactos ambientais, adotados por alguns países a partir das décadas de 1960 e 1970, mais que uma resposta às preocupações coletivas, converteu-se em via preferencial utilizada pelos Poderes públicos com vista à pacificação ambiental. Em outras palavras, o enfoque ou a orientação política do Direito ambiental foram de estipular parâmetros técnico-ecológicos toleráveis, que inculcados no ordenamento normativo vigente, apresentam-se como salvaguardas da sociedade e do diversificado entorno inerente.

Sobre o influxo técnico-ecológico, ou, ainda, "orientação ecológica", promovido pela tecnicidade das ciências naturais no Direito, segundo Esteve Pardo, tratase de um fato que a história confirma. Esclarece que durante séculos a conexão entre esses saberes foi bastante próxima, pois às vezes coincidia que o mais prestigioso jurisconsulto era, ao mesmo tempo, um destacado matemático ou especialista das ciências naturais; disciplinas essas que apoiaram e sustentaram correntes e doutrinas jurídicas em sua época quase hegemônicas. Expõe que, no período do Iluminismo, os avanços das ciências teóricas e físicas tiveram forte influência nas doutrinas políticas; o mesmo ocorreu com a lei, que se construiu como neurálgica influência newtoniana, que tanto contribuiu para exaltar a lei até 24 HERMITTE, Marie - Angèle. La fundación jurídica de una sociedad de las ciencias y de la técnica a través de las crisis y de los riesgos. In: DIAS VARELLA, Marcelo (Org.). Derecho, Sociedad y riesgo. La sociedad contemporánea vista a partir de la idea de riesgo: Rede latinoamericana y europea sobre gobierno de los riesgos. Brasília: UniCEUB, UNITAR, 2007. p.13-63. p.41 e 42. 
sua consolidação como enunciado inabalável ${ }^{25}$. Atualmente, como um processo histórico contínuo, preexiste deliberada remissão do Direito ambiental aos conceitos extraídos das ciências naturais, tais como geologia, biologia, hidrologia e outras, que, em conjunto, vêm a compor a ecologia ${ }^{26}$.

Emumcenário dedeterminismotecnológico, modernidadetécnicaeproblemática ambiental, tentar compreender o Direito, mais especificamente o Direito ambiental, como uma ciência social aplicada, que fora modelada ou de alguma forma (des) orientada pela faceta técnica-ecológica da ciência, precisamente pelas ciências naturais, é uma tarefa bastante espinhosa e pouco referendada. No entanto já se pode antecipar que, ao tentar regular os efeitos ambientais da materialização técnica e industrial no entorno por meio de normas jurídicas, sem dúvida, parece encontrar-se fortemente influenciado por essa classe de lógica tecnicista.

Portanto se observa, desde a perspectiva jurídica, que a ainda embrionária especialidade ambiental foi golpeada energicamente por referida concepção técnica, talvez por havernascidojunto com o processo de tecnificação da intervenção pública e hoje, mais que nunca, a mesma corresponderá gerir a aplicação da técnica no entorno, sem que a mesma impacte nocivamente outros direitos que igualmente resguarda historicamente. Ou seja, o Direito ambiental deve lograr dirigir o progresso técnico, industrial e econômico, pois é necessário em um contexto de sustentabilidade, ao mesmo tempo, não pode permitir que esse avanço vá além da tolerabilidade ecológica e socioeconômica; aceitabilidade que dependerá, em grande medida, do grau de mitigação das soluções interdisciplinares propostas por esse mesmo avanço científico, social e econômico.

Devido à indução promovida pelas ciências naturais e suas técnicas, os aplicadores do Direito já estão bastante acostumados, ao perseguir concretizar a interpretação da norma jurídica ambiental, a recorrer às normas técnicas de segurança e à qualidade industrial; a enfrentar a discricionariedade administrativa e judicial, de conteúdo altamente técnico; deparar-se com dispositivos normativos

25 ESTEVE PARDO, José. Técnica, riesgo y derecho: tratamiento del riesgo tecnológico en el derecho ambiental. Barcelona: Ariel, 1999. p.13 e ss.

26 ESTEVE PARDO, José. EI desconcierto del Leviatán: política y derecho ante las incertidumbres de la ciencia. Madrid: Marcial Pons, 2009. p.130 
em forma numérica, tais como padrões de emissão e imissão de contaminantes; igualmente há de solicitar perícias expertas para valorar danos ambientais; e, por último, exemplificativamente, há de se encontrar com incontáveis conceitos jurídicos indeterminados e extrajurídicos, que impregnam a normativa, tais como impacto ambiental, fragilidade e vulnerabilidade ambiental, que são elucidados normalmente por expertos dedicados ao estudo dos fatores físico-naturais que, em cada momento, segundo o avanço técnico-ecológico alcançado, estabelecerão os ditames ambientais apropriados. Conseguinte, normalmente, salvo um infrequente juízo interdisciplinar, será essa classe unidimensional de interpretação técnica que esculpirá vários dos atos administrativos, legislativos e judiciais dirigidos à proteção ambiental. Ou seja, o influxo técnico-ecológico está profusamente incorporado à rotina dos órgãos ambientais e setoriais ao interpretarem a norma ambiental, produzida ou não pelo legislativo. Inclusive, em efeito cascata, essa orientação se infere corriqueiramente na jurisprudência, especialmente em temas relacionados à contaminação e à degradação ambiental, como bem atesta exemplo pátrio ${ }^{27}$, que assim se expõe:

A interpretação das normas que tutelam o meio ambiente não comportam apenas, e tão somente, a utilização de instrumentos estritamente jurídicos, pois é fato que as ciências relacionadas ao estudo do solo, ao estudo da vida, ao estudo da química, ao estudo da física devem auxiliar o jurista na sua atividade cotidiana de entender o fato lesivo ao Direito Ambiental.

Presumidamente, ao se amparar energicamente em tais conhecimentos e soluções técnicas, o Direito se mostra apto a prognosticar fatos ambientais presentes e futuros. Ou seja, sobretudo com o suporte nos resultados da experiência ecológica, a ciênciajurídica, guarnecida pela interpretação extrajurídica de suas normas, persegue ordenar tecnicamente o ambiente segundo exigências temporais dos processos decisórios. Esse artifício ou remissão jurídica ao mundo da técnica, se por um lado evidencia e promove uma estratégica saída ante a problemática ambiental, ainda que parcial, de orientação técnica-ecológica, por

27 BRASIL. Segunda Turma do Superior Tribunal de Justiça. Recurso Especial no 1.094.873 - SP. Ministros Humberto Martins, Herman Benjamin, Mauro Campbell Marques, Eliana Calmon e Castro Meira. Relator Ministro Humberto Martins. Brasília (DF), 04 de agosto de 2009 (Data do Julgamento). DJ: 17/08/2009. 
outro, mostra, não obstante, sua limitação como meio de regulação da técnica, haja vista ter seu próprio âmbito de produção, e ostenta na atual conjuntura jurídica privilégios no campo motivacional de atos administrativos, legislativos e judiciais. Trata-se de um emergente costume técnico, que se mostra habitual no sistema de fontes e hermenêuticos do Direito ambiental. Em outros termos, as técnicas e os labores das ciências naturais são autênticas e indispensáveis fontes do Direito, quando este por si mesmo, ou por suas tradicionais fontes, não encontra solução rigorosamente jurídica a um conflito ambiental.

Dependência que é destacada por Ramón Martín Mateo, ao ensinar que os graves perigos que acercam o homem e seu entorno provêm do desigual desenvolvimento dos padrões de comportamento social frente à exploração das leis naturais. Ressalta que é necessário integrar os resultados das ciências experimentais e tecnologias, com os pressupostos e as correções precisas desde o campo da Política, da Ética, da Antropologia e do Direito, que, entretanto, costumam vir atrás dos avanços promovidos pelas ciências naturais ${ }^{28}$. Isto é, destaca que o Direito ambiental, como regra geral, segue, todavia, sustentando-se marcadamente nos ditames elaborados pelos profissionais correspondentes às disciplinas, como física, biologia, ecologia, além das tecnologias que as aplicam ${ }^{29}$.

Destaca que, por muito que avancem as ciências naturais, é necessária a intervenção dos Poderes públicos para obter novos conhecimentos científicos e, sobretudo, para que haja uma aplicação técnica mais consciente. Isto é, as inovações no âmbito das ciências naturais são seguramente um pré-requisito para conseguir não só recursos necessários, mas, também, para propiciar que a manipulação técnica seja assimilável em termos ambientais, e desde as ciências sociais, cabe intervir promovendo as medidas necessárias para que as inovações adequadas se promovam ${ }^{30}$. No mesmo sentido, Alenza García assevera que a dimensão jurídica do Direito ambiental é algo que não pode ficar em segundo

28 MARTÍN MATEO, Ramón. El hombre: una especie en peligro. Madrid: Campomanes Libros, 1993. p.83.

29 MARTÍN MATEO, Ramón. Manual de Derecho Ambiental. 3. ed. Navarra: Aranzadi, 2003. p.56.

30 MARTÍN MATEO, Ramón. Tratado de Derecho Ambiental. Tomo IV. Madrid: Edisofer. 2003. p.87. 
plano, pelo fato de se apoiar nas ciências de cunho ecológico, pois sua base axiológica impede que a regulação do ambiente se reduza a uma mera tradução proposta pelas ciências naturais e, portanto, demanda que esteja presente os postulados valorativos da sociedade na regulação que se leve a cabo ${ }^{31}$.

Em suma, o Direito ambiental apresenta um componente técnico cuja significação, mais que acessória e subordinada, é um elemento central e característico tanto da regulação normativa como da valoração que se constrói uma decisão jurídica. Não trata apenas de singelo dado complementar, que se confina em um momento procedimental, na verdade, constitui-se em muitos casos a referência básica para resolução da diligência jurídica ${ }^{32}$. Portanto se deduz que um mínimo de conhecimento do conteúdo das diversas ciências naturais, conhecimento extrajurídico, é condição sine qua non para a correta localização e interpretação das normas jurídicas de vertente ambiental ${ }^{33}$. Logo, se a linha divisória entre o legal e a proibição ambiental constitui objeto jurídico, as bases científicas em que se assenta sua delimitação extrapolam por completo as margens do Direito e do sistema jurídico, já que se abrem às interferências racionais das ciências naturais. Sem embargo, em momentos de incerteza científica, a certeza buscada pelo Direito ambiental em suas normas jurídicas se vê comprometida ao servir como critério valorativo e preditivo das instituições públicas envolvidas na temática. Assim que a certeza científica corta a segurança jurídica, seja na elaboração da norma, seja em sua respectiva aplicação ${ }^{34}$.

Finalmente, apesar de todas as limitações e deficiências que acomete a ciência, em especial as ciências naturais, pode-se ajuizar que há um enfoque técnicoecológico enraizado no ordenamento jurídico ambiental, pois são inumeráveis os momentos em que se busca controlar e garantir a tolerabilidade dos comportamentos significativamente impactantes, por meio de normas e estudos

31 ALENZA GARCÍA, José Francisco. Manual de Derecho ambiental. Pamplona: Universidad Pública de Navarra. 2001. p.51.

32 ESTEVE PARDO, José. El componente técnico del Derecho del medio ambiente. Limitaciones y posibilidades de los entes locales. In: ESTEVE PARDO, José (Coord.). Derecho del medio ambiente y Administración Local. Madrid: Civitas. 1996. p.451-463. p.451.

33 ALONSO GARCÍA, Enrique. Legislación sectorial de Medio Ambiente. Revista de Administración Pública, Madrid, n.137, p.57-92. mayo-agosto 1995. p.60.

34 CRUZ, Branca Martins da. Responsabilidade civil pelo dano ecológico: alguns problemas. Revista de Direito Ambiental, São Paulo, n. 5, p. 5-41. 1997. p.27. 
baseados em uma verdade físico-natural. Referido cenário põe manifesto que a desígnio do Direito ambiental é localizar a interpretação jurídica no conteúdo parecerista e nas normas vinculadas às ciências da natureza que, sem embargo, ainda que tenham muitos êxitos e resultados benéficos, em muitas ocasiões, ostentam vacuidades e lacunas científicas. Além disso, deve-se acrescentar que, em muitas oportunidades são operadas por expertos que padecem de incipiente habilidade ou reputação técnica, ou pior, podem representar deliberadamente escusos interesses de setores técnicos e industriais fortemente implicados na (des)configuração de espaços urbanos e naturais.

\section{INTEGRAÇÃO CIENTÍFICA}

Ao final do século XIX e início do XX, o êxito das ciências naturais e da tecnologia reivindicava com urgência uma análise da fundamentação teórica das ciências sociais ${ }^{35}$. Sem embargo, o despertar das disciplinas de cunho social, preocupadas pela incorporação da variável ambiental, situa-se na década de 1960; arranque que coincide com o período de reconstrução social da ciência, da tecnologia e dos riscos ambientais, em um mundo dominado pela insegurança gerada pela corrida belicista e nuclear ${ }^{36}$. No âmbito acadêmico, a incorporação da variável ambiental se produziu de forma morosa, e, todavia, com enfoques disciplinares tradicionais. Foi abordada de forma pioneira pelas ciências naturais e, posteriormente, pelas ciências sociais. No entanto, ainda nos dias de hoje, são as primeiras que têm protagonismo no debate ambiental contemporâneo ${ }^{37}$. Nesse sentido, Sempere e Riechmann clarificam que as conexões entre ecologia e sociedade foram praticamente ignoradas, salvo honrosas exceções de alguns científicos naturais e sociais da segunda metade do séc. XIX e, atualmente, ainda que esteja longe de uma completa integração, as ciências sociais incorporam cada vez mais essas conexões, assim como é mais frequente a percepção do transfundo

35 GÓMEZ HERAS, José María G. El apriori del mundo de la vida: fundamentación fenomenológica de una ética de la ciencia y de la técnica. Barcelona: Anthropos, 1989. p.125.

36 LEMKOW, Louis. Sociología ambiental. Pensamiento socioambiental y ecología social del riesgo. Barcelona: Icaria, 2002. p.9 e 10.

37 PARDO BUENDÍA, Mercedes. La evaluación del impacto ambiental y social para el siglo XXI: teorías, procesos, metodología. Madrid: Fundamentos. 2002. p.21. 
ecológico, antes insuspeito, de numerosos conflitos políticos e sociais ${ }^{38}$.

Por outro lado, Irigalba, Etxaleku e Echavarren, amparados em extensa literatura, destacam que a integração dos aspectos sociais e ecológicos no discurso científico e social pode resultar para muitos um fato inquestionável, mas na verdade ainda não é uma proposta tão comumente aceita, pois se estudam, por um lado, os aspectos ecológicos e, por outro, os aspectos socioeconômicos. Esta divisão analítica pode haver resultado útil em outros tempos, porém não é correta, porque separa, divide e, sobretudo, exclui.

Desde as ciências sociais é conhecido que a complexidade ambiental não é fragmentaria, nem se apresenta atomizada, pelo contrário, é diversa, multicausal, interdependente, global e integradora. Essa assertiva implica que os expertos sociais devem ser muito conscientes da responsabilidade que tem ao intervir tecnicamente, em todas as formas que podem fazê-lo: preventiva, corretiva, facilitadora, transformadora e reparadora. Em relação à direcionalidade dessa relação integradora entre o social e o ecológico, propõem que se deve integrar o social no ecológico, mas não se deve esquecer das possibilidades que se abrem ao contrário, inserir o ecológico no social. Contrapostamente, acrescentam que, em geral se tende mais a aportar, a modo de complemento, a dimensão social nas análises ecológicos, como se fora para lembrar que ficariam inconclusas se não tem em conta que o cidadão é um elemento biótico a mais, além de personagem chave do ambiente. Já desde as ciências sociais custa mais introduzir o ponto de vista ecológico, em seu sentido mais físico-natural, e realizar análises contextualizadas desde esta perspectiva interdisciplinar ${ }^{39}$.

A demanda por indicadores interdisciplinares para a sustentabilidade demanda novos desafios ao conhecimento científico, já que, conforme indica Brian Wynne, deve-se ter em conta que o conjunto nada depreciável de trabalho científico investido nas últimas décadas para criar modelos de avaliação do risco ambiental não pode se tomar como uma presunção de que

38 SEMPERE, Joaquim; RIECHMANN, Jorge. Sociología y medio ambiente. p.12.

39 IRIGALBA, Ana Carmen; ETXALEKU, Ana Isabel; ECHAVARREN, José M. La evaluación de impacto ambiental: Recopilación, análisis y punto de vista crítico desde la perspectiva sociológica. In: ALEDO TUR, Antonio; DOMÍNGUEZ GÓMEZ, José Andrés (Directores). Sociología Ambiental. Granada: Grupo Editorial Universitario, 2001. p.361-403. p.362 e 363. 
as dimensões importantes dos impactos produzidos pela ação técnica tenham sido explicadas de modo conclusivo. Compreender isso não requer apenas o estudo das interpretações que compete à determinada área de interesse, também exige, a um nível muito mais profundo, uma aprendizagem reflexiva acerca da natureza e das limitações inerentes ao conhecimento científico, por mais acurado que se tenha produzido ${ }^{40}$.

Em um número importante de casos, já resulta evidente que o êxito dos enfoques científicos estratificados levou ao agravamento dos problemas ambientais e de desenvolvimento que pretendiam solucionar. Vários processos contribuem para esse cenário, entre eles aparece a introdução da incerteza, devido tanto à compreensão incompleta dos processos humanos e ecológicos, como ao indeterminismo inerente aos sistemas complexos e à variedade de interesses e decisões envolvidas. Assim que a complexidade inerente à sustentabilidade, caracterizada por situações em que se superpõem dinâmicas ecológicas e sociais, implica muitos casos a necessidade de incorporar percepções e interesses de distintos atores sociais, haja vista a inquestionável importância de combinar o conhecimento popular com o científico ${ }^{41}$.

Dessa forma, impõe-se um chamamento ao Direito, à Economia, à História, à Literatura eà Arte, para que se aprofundem em suas próprias investigações e gerem cenários aptos a trasladar o indivíduo a um nível moral mais elevado; condição que poderá ser alcançada quando haja um progresso paralelo das distintas categorias de ciências, sejam elas sociais, naturais e humanísticas. Esse avanço constituirá em uma premissa nem tanto de desenvolvimento, mas, sobretudo, de aplicação reflexiva dos avanços científicos. Em efeito, como consequência do desenvolvimento extemporâneo das ciências sociais e humanidades frente às ciências naturais, produz-se um difuso estado de incerteza e insatisfação ${ }^{42}$.

40 WYNNE, Brian. Incertidumbre y aprendizaje ambiental: reconcebir la ciencia y la política en un paradigma preventivo. In: GONZÁLEZ GARCÍA, Marta I.; LÓPEZ CEREZO, José A.; LUJÁN, José Luis (Eds.). Ciencia, tecnología y sociedad: lecturas seleccionadas. Traducción Mario Francisco Villa. Barcelona: Ariel, 1997. p.161-183. p.164.

41 CEPAL. Ciencia y tecnología para el desarrollo sostenible. Disponível em: http://repositorio.cepal.org/bitstream/handle/11362/6538/S0316_es.pdf?sequence $=1$. Acesso em: 31/12/2014.

42 PAPI, Giuseppe Ugo. Técnica y humanismo. Revista de estudios políticos, Madrid, n.153154, p.29-42. mayo y agosto 1967. p.32. 
Destacam Funtowicz e Ravetz que a ciência evolui na medida em que é capaz de contestar os principais desafios de uma época. A maior tarefa coletiva que hoje deve solucionar a sociedade refere-se aos problemas inerentes aos riscos ambientais e àqueles relacionados à equidade social entre os cidadãos. Porém, ainda que tardiamente, já se estão desenvolvendo novos estilos de atividade científica, que superam as oposições tradicionais entre disciplinas pertencentes ao campo das ciências naturais e sociais, entre ciências chamadas "duras" e "brandas". Enfim, já se observa a transição da visão reducionista analítica, de especialidades cada vez mais particularizadoras, a um enfoque sistêmico, sintético e humanístico, que reconhece os sistemas naturais como complexos e dinâmicos, cuja base é a imprevisibilidade, a observação incompleta e a pluralidade de enfoques legítimos ${ }^{43}$.

Sendo assim, a integração das ciências naturais e sociais deve ter consequências não apenas sobre o próprio conceito de ciência, mas também sobre o método pelo qual a ciência tem que se servir, visto que realidades distintas não podem ser reveladas por conceitos iguais, nem por meio de um método único. A ciência no social deve levar em consideração o caráter contraditório da realidade, o que inevitavelmente configura seu próprio conceito de ciência e, por consequência, o método de aproximação da realidade ${ }^{44}$.

Em uma perspectiva científica globalizante, Medina Gómez relata que os desafios mais fundamentais para as culturas do século XXI, em geral, e para os estudos científicos, em concreto, têm a ver não apenas com a compressão da tecnociência, mas, também, de uma maneira especial, com os modelos de valoração e intervenção que possam manejar os impactos e as crises geradas pelas transformações e pelas globalizações tecnocientíficas. Atualmente, todo projeto que pretenda ter em conta a complexidade global da tecnociência há de partir de concepções capazes de integrar todas as dimensões, ecológica, social e econômica. Para isso, deve deixar atrás as antigas concepções divisórias da

43 FUNTOWICZ, Silvio O.; RAVETZ, Jerome R. La ciencia posnormal: ciencia con la gente. Barcelona: Icaria, 2000. p.23.

44 CAMBRA BASSOLS, Jordi de. La teoría crítica y el problema del método en las ciencias sociales. Reis: Revista española de investigaciones sociológicas, Madrid, n.17, p.5364. 1982. p.54. 
ciência e se sintonizar a uma perspectiva científica global e integradora ${ }^{45}$.

Portanto, o que se propõe é levar a cabo uma reflexão sobre a necessidade de integrar os enfoques das ciências sociais, naturais e humanidades no estudo dos fatores associados à problemática ambiental. Ou seja, com o enfoque técnico-ecológico, próprio das ciências naturais; e a orientação técnico-social de outro, própria dos conhecimentos e saberes sociais envolvidos, com a devida interação de ambos, acredita-se que a ciência poderá aprovisionar, como consequência, soluções políticas e jurídicas mais eficazes ante a incerteza interdisciplinar associada aos impactos ambientais do modelo de desenvolvimento propugnado. Em outras palavras, desde a perspectiva do Direito, a integração das ciências sociais e naturais deve ser o propósito principal da política ambiental e tecnológica, pois ambas, se por um lado cumprem objetivos técnico-ecológicos, igualmente devem admitir e considerar critérios e parâmetros ofertados por distintos expertos e segmentos sociais, que têm suas próprias fontes e técnicas de conhecimento ambiental; híbrido cenário jurídico que consolidará a interdisciplinaridade demandada pela sustentabilidade, de evidente orientação socioecológica.

\section{CIÊNCIA E DIREITO DA SUSTENTABILIDADE}

A complexa interação meio ambiente e desenvolvimento se estabelece sobre o termo sustentabilidade, cujo conceito original se relaciona e foi permutado das experiências agrobiológicas, em que o relaciona com a capacidade do sistema agrícola manter a produtividade frente às adversidades. Nos meios conservacionistas, primeiramente, a sustentabilidade foi encarada com critérios fundamentalmente ecológicos frente aos sistemas naturais. Finalmente, o conceito transcendeu a faceta estritamente ecológica e incorporou a dimensão ambiental em sua plena acepção, incluindo, portanto, progressivamente, critérios econômicos, sociais e culturais ${ }^{46 ;}$ nesse sentido, já ensinava Enrique Leff que o

45 MEDINA GÓMEZ, Manuel. Tecnociencia y cultura. Concepciones, impactos y retos. In: MARQUÉS RODILLA, Cristina (Coord.). El impacto social de la cultura científica y técnica. Madrid: Ministerio de Educación, Cultura y Deporte, Secretaría General Técnica. Subdirección General de Información y Publicaciones. 2004. p.47-96. p.48.

46 JIMÉNEZ HERRERO, Luis M. Desarrollo sostenible: transición hacia la coevolución global. 
"ambiente não é a ecologia, mas a complexidade do mundo"47.

A tensão ambiental (ecológica), social e econômica inerente à sustentabilidade está cada vez mais incrustada na consciência política e coletiva, haja vista sua presença no debate público nacional e internacional, como bem apontam Real Ferrer, Glasenapp e Cruz. Acrescentam que, cronologicamente, pode-se observar que o nascedouro do tema, primeiro "impulso" ou "onda" política inerente, deu-se com uma publicação da Comissão Mundial sobre o Meio Ambiente e Desenvolvimento (1987), nomeado Informe Brundtland, que veio a conceber e promover o paradigma do desenvolvimento sustentável, assim como incitar a realização da primeira conferência das Nações Unidas sobre o Meio Ambiente (1972), que por sua vez demarcou a origem do Direito Ambiental. Passadas duas décadas, as Nações Unidas organizaram a Conferência sobre o Meio Ambiente e o Desenvolvimento (1992). A chamada conferência Cúpula da Terra, segunda onda política para a sustentabilidade, realizada no Rio de Janeiro, veio a consolidar o Direito ambiental como um emergente ramo jurídico. Como terceiro impulso político, na tentativa de incrementar os discursos e os esforços coletivos, promoveu-se a Conferência das Nações Unidas sobre o Meio Ambiente de Johannesburgo (2002) ou Rio+10, que ratificou o compromisso global para o desenvolvimento sustentável.

No contexto da solidariedade global, a Rio $+10 \mathrm{fez}$ a troca do conceito de desenvolvimento sustentável por sustentabilidade, e consagrou em definitivo, em ampla dimensão, a perspectiva ecológica (proteção ambiental), social (desenvolvimento social) e econômica (desenvolvimento econômico) associada ao tema. Portanto, só a partir de 2002 é que passa a ser adequado utilizar a expressão 'sustentabilidade', em vez de desenvolvimento adjetivado como 'sustentável'48, isso porque, como bem ensina Real Ferrer, "la sostenibilidad debe ser entendida como la meta global a alcanzar y el desarrollo sostenible como uno de los instrumentos que deben permitir su consecución."

Madrid: Ediciones Pirámide. 2000. p.100.

47 LEFF, Enrique. Epistemologia Ambiental. 3. ed. Tradução de Sandra Valenzuela. São Paulo: Cortez, 2002. p.17.

48 REAL FERRER, Gabriel; GLASENAPP, Maikon Cristiano; CRUZ, Paulo Márcio. Sustentabilidade: um novo paradigma para o direito. Revista Novos Estudos Jurídicos. Itajaí. v.19, n.4, p.1433-1464. 2014. p.1445 e ss. 
Após sumária aproximação sócio-histórica-institucional ao nascimento do que se rotula como sustentabilidade, assim como antes de perquirir o que venha a ser designado como Direito da Sustentabilidade, devido à unicidade do conhecimento cientifico, deve-se remeter ao que se trata de forma vanguardista em alguns canais científicos, como Ciência da Sustentabilidade, Sustainability Science ou Science and Technology for Sustainable Development, conforme terminologia anglo-saxônica, que se apresenta como um chamamento aos estudiosos e pesquisadores das ciências sociais e naturais, meio ao influxo transdisciplinar demandado, a extrapolarem o caráter atomizado de suas disciplinas, para que logo seus produtos intelectuais sejam mais eficazes ao servirem de apoio à gestão socioecológica da problemática ambiental que se apresenta "glocalmente". Ou seja, como bem destaca Joon Kim e Taikan Oki, a ciência da sustentabilidade surge como estimulante campo científico e educacional, posto que extrapola as fronteiras disciplinares e se dirige, progressivamente, em apreender a dinâmica dos sistemas socioecológicos. ${ }^{49}$

A ausência de teorias sobre a interação natureza-sociedade ainda se mostra como uma barreira para sustentabilidade, ainda que esteja surgindo uma série de novos enfoques científicos, de diferentes origens e tendências, com virtudes e debilidades, que visem preencher essa lacuna existente entre as ciências naturais e sociais. Deve-se destacar que, igual ocorrido no princípio da conscientização ambiental, as questões referentes à sustentabilidade foram primeiramente abordadas pelas ciências naturais, e só posteriormente reconhecidas como importantes pela sociedade e pelos operadores das ciências sociais. Sendo assim, para reconceituar e reformular a ciência em consonância com os desafios da sustentabilidade, é exigível o esforço e a inovação que seja capaz de repensar em uma abordagem integral e adequada a levar em consideração os conhecimentos, os métodos e as técnicas das ciências naturais, sociais e humanidades. ${ }^{50}$

Atendo-se que se trata de uma construção sobretudo acadêmica, tem-se que importante marco para o estudo da chamada Ciência da Sustentabilidade

49 KIM, Joon; OKI, Taikan. Visioneering: an essential framework in sustainability science.

Sustainability Science. v. 6, n. 2, p. 247-251, 2011. p.247.

50 JERNECK, Anne et al. Structuring sustainability science. Sustainability Science, v. 6, n. 1, p.69-82. 2011. p.74 e 78. 
remonta ao ano 2000, por meio da Reunião de Friibergh Manor, na Suécia, em que dezenas de investigadores, provenientes das ciências naturais e sociais, indicaram a necessidade de promover um novo campo de indagação científica e tecnológica. Como consequência do encontro, e outras oficinas realizadas em distintas partes do mundo, originou a pioneira Initiative on Science and Technology for Sustainability, composta por intelectuais e instituições comprometidas com a sustentabilidade ${ }^{51}$.

A Ciência da Sustentabilidade é consideravelmente distinta em estrutura, métodos e conteúdo da ciência tal e como se conhece ${ }^{52}$, posto que implica manejar simultaneamente as ciências naturais e sociais e reconhecer as limitações do conhecimento científico tradicional para abordar as complexas relações socioecológicas. Dessa forma, impõe-se que a ciência rompa os paradigmas de uma inapropriada dicotomia entre ciências naturais e sociais, que de forma inadequada evoluíram de forma relativamente independente.

O tratamento das interações socioecológicas impõe que a Ciência da Sustentabilidade ostente algumas características básicas, que se pode resumir da seguinte maneira: deve ser fortemente interdisciplinar ao abordar desafios ambientais complexos; para promover a sustentabilidade é necessário inserir na investigação e nos processos de tomada de decisão, o público leigo, visto que, ainda que não faça parte dos ambientes científicos e acadêmicos, seus interesses, experiências e intervenções resultam imprescindíveis para definir e pôr em marcha estratégias que viabilizem a transição para sustentabilidade; e as estratégias devem responder a uma perspectiva espacial e temporal ampla, ou seja, espacialmente, deve ser "glocal", global e local simultaneamente e, temporalmente, deve contemplar objetivos, tendências, riscos e barreiras ambientais em curto, médio e longo prazo. ${ }^{53}$

Por outro lado, deve-se ressaltar que o surgimento da chamada Ciência da Sustentabilidade não deve afetar negativamente a evolução particularizada de cada

51 CEPAL. Ciencia y tecnología para el desarrollo sostenible.

52 KATES, R. W. et al. Sustainability Science. Science, v.292, n.5517, p.641-642. 2001. p.641.

53 VILCHES, Amparo; GIL-PÉREZ, Daniel. Ciencia de la Sostenibilidad. Revista Eureka sobre

Enseñanza y Divulgación de las Ciencias, v.11, n.3, p.436-438, 2014. p.436. 
ciência, tampouco afetar a diversidade terminológica, que é fruto de uma evolução histórica e disciplinar. Em outros termos, seguirá existindo e se desenvolvendo a Química Verde, a Física Ambiental, a Educação Ambiental"54, e aqui aplicável, o Direito ambiental. Nesse sentido, dedicado a afrontar epistemologicamente a problemática ambiental desde o Direito, em linha com essa avançada perspectiva no estudo da ciência dedicada a apreciar as intricadas relações socioecológicas da sustentabilidade, é a do mestre Gabriel Real Ferrer, que destaca que a capacidade de integração científica e expansão do tradicional Direito ambiental se dará quando existir sua conexão com um "novo" direito emergente, adjetivado pela sustentabilidade, ou seja, o Direito da Sustentabilidade, cujo enfoque integral, se incorporado aos instrumentos e aos artifícios do Direito ambiental, garantiria que o paradigma da sustentabilidade, de cunho ecológico (ambiental), social e econômico, pudesse se levar a cabo desde a perspectiva jurídica ${ }^{55}$.

Em outro momento, destaca que o Direito da Sustentabilidade é um direito concebido em termos de espécie e como mecanismo de resolução de problemas globais, que contempla parte da estrutura da ordem jurídica, social, econômica e ambiental inerente aos Estados soberanos, mas que extrapola ao âmbito transnacional, haja vista que sua disposição é proporcionar recursos e soluções que convenham a todos os cidadãos e aportar segurança à sociedade futura e global ${ }^{56}$; sociedade sustentável que deverá atender a alguns atributos: ser planetária, sem inclinações nacionalistas ou regionais; comprometida com a capacidade de suporte e de reposição dos fatores ambientais (ecológicos ou físico-naturais); persiga reformular as relações de poder e reparto de riquezas e ônus ambientais; politize a globalização por meio da governança; e que promova uma ciência e tecnologia dirigida a objetivos comuns e mitigadores ${ }^{57}$.

54 VILCHES, Amparo; GIL-PÉREZ, Daniel. Ciencia de la sostenibilidad: Un nuevo campo de conocimientos al que la química y la educación química están contribuyendo. Educación química, v.24, n.2, p.199-206, 2013. p.205.

55 REAL FERRER, Gabriel, "El Derecho ambiental y el derecho de la sostenibilidad". Palestra proferida em 17 de julho de 2007 no "Cuarto Programa Regional de Capacitación en Derecho y Políticas Ambientales", em San Salvador, organizado pelo Programa das Nações Unidas para o Meio Ambiente (PNUMA), Ministerio de Medio ambiente y Recursos Naturales de El Salvador, Ministerio de Medio Ambiente de España e Naciones Unidas.

56 REAL FERRER, Gabriel. Calidad de vida, medio ambiente, sostenibilidad y ciudadanía ¿Construimos juntos el futuro? Revista Novos Estudos Jurídicos. Itajaí. v.17, n.3, p.310-326. 2012. p.320

57 REAL FERRER, Gabriel. Sostenibilidad, transnacionalidad y transformaciones del derecho. 
Portanto o Direito da sustentabilidade trata-se de direito tripartido em sua unicidade, pois é solidário, continente e expansivo de cara ao Direito ambiental, esse que, inadvertidamente, é habitualmente mais atento à faceta técnica-ecológica do conhecimento científico. Em consequência, em um marco cartesiano mais avançado, humanístico e socialmente globalizado, infere-se que as partes da ciência jurídica adjetivada pela sustentabilidade, ou melhor dito, do Direito ambiental (da sustentabilidade), são: o "tradicional" Direito ambiental, que propicie melhores instrumentos e condições tecnológicas e físico-naturais para a vida; o Direito das relações sociais (sustentáveis), a faceta ou orientação técnico-social, cultural, ética e institucional, responsável pela estruturação dos processos de tomada de decisão e governança política, administrativa, social e transnacional dos desafios inerentes à sustentabilidade; e o Direito econômico da sustentabilidade, relacionado com as técnicas de geração e repartição dos benefícios e prejuízos econômicos, oriundos dos impactos positivos e negativos, inerentes à apropriação dos fatores da sustentabilidade.

Em outras palavras, o Direito ambiental, desde que redirecionado ou redimensionado pela sustentabilidade, estará apto a ser um disciplinamento científico "pós-moderno" ou "pós-normal", pois de modo manifesto contribuirá para complementar e expandir o paradigma científico hodierno, isto é, não só da ciência jurídica, mas também da própria ciência geral, já que a aplicação isolada da modernidade técnica resulta parcial e disfuncional frente ao objetivo tridimensional buscado pelo paradigma da sustentabilidade. É um direito que emprega a lógica da solidariedade intergeracional na humanidade, vinculando diretamente as desgraças do futuro às decisões socioecológicas do presente, mas, que, sobretudo, impõe uma nova contextualização jurídica das ciências e da sua aplicabilidade prática no entorno.

Ainda sobre o tema, Gabriel Real Ferrer ensina que o princípio jurídico e também, desde outra perspectiva, o embasamento ético que devem presidir

In: SOUZA, M. C. S. A.; GARCIA, D. S. S. (Orgs.). Direito ambiental, transnacionalidade e sustentabilidade. Itajaí: UNIVALI, 2013. Disponível em: http://siaiapp28.univali.br/ LstFree.aspx Consultado em: 25/03/2015. Publicado previamente em: Revista de Derecho Ambiental: Doctrina, Jurisprudencia, Legislación, Práctica. Buenos Aires, n.32, p.65-82, out./dez. 2012. 
o Direito da Sustentabilidade é a solidariedade. Em ambas as perspectivas, a solidariedade é a base em que se deve construir a sociedade transnacional que se forma e o Direito que deverá conduzi- $\mid a^{58}$. Enfatiza que, para que a solidariedade ou a codependência sustentáveis sejam levadas a cabo, demandam-se regras ou normas que as positive, condição que impõe ao Direito, em especial ao Direito público, se não outra estratégia que a de se inspirar nesse status metaindividual, acima dos interesses setorizados ou individuais, para esculpir o ordenamento jurídico que se pretende à sustentabilidade ${ }^{59}$.

Sobre exigível remontada do ordenamento jurídico ambiental, Ramón Martín Mateo ensina que não é necessário recordar que a legislação gerada em distintos níveis ainda estabelece uma resposta intempestiva aos danos produzidos pela industrialização, visto que o funcionamento dos sistemas naturais é infinitamente mais complexo e errático do que se pensa. Portanto, demanda-se uma sólida ambição dos juristas, que devem encontrar no ordenamento jurídico campo fecundo e aberto a se revigorar conforme as tendências do desenvolvimento científico. Destaca que todas as matérias que se cultivam nas faculdades de Direito estão aqui implicadas, incluído o Direito romano, do qual procede o mecanismo de emissão-imissão, que é uma das chaves para compreender o substrato básico da problemática ambiental ${ }^{60}$.

58 Nesse sentido, Miglino, Cruz e Soares ensinam que: "O Direito que adviria de um ambiente político-jurídico transnacional seria forjado, muito provavelmente, com base em princípios de inclusão social e proteção ao ambiente. A sustentabilidade e a solidariedade passariam a ser os principais itens da pauta do milênio. Neste novo modelo de organização social que está por surgir, é essencial que os princípios de uma formação humanista que servira de base para a construção da civilização ocidental sejam atualizados ao modo como a humanidade se encontra na realidade contemporânea, não se perdendo por esta via a busca por realização do valor humano nesta reorganização política." In: Possibilidades para a transnacionalidade democrática. Revista Novos Estudos Jurídicos. Itajaí. v. 15, n. 2, p. 193-211. 2010. p.197. Deve-se salientar a existência da linha de pesquisa titulada "Estado, Transnacionalidade e Sustentabilidade" do curso de Doutorado em Ciência Jurídica da UNIVALI, cuja direção cumpre ao Prof. Dr. Paulo Márcio Cruz, e conta com a participação docente de juristas como Manuel Atienza (Universidade de Alicante - Espanha), Michel Prieur (Universidade de Limoges - França), José Rubens Morato Leite (UFSC - Brasil), Cesar Luiz Pasold (UNIVALI) e outros de renomado prestígio.

59 REAL FERRER, Gabriel. Sostenibilidad, transnacionalidad y trasformaciones del derecho. In: SOUZA, M. C. S. A. ; GARCIA, D. S. S. (Orgs.). Direito ambiental, transnacionalidade e sustentabilidade.

60 MARTÍN MATEO Ramón. La revolución ambiental pendiente. In: PIÑAR MAÑAS, José Luis (Dir.). Desarrollo Sostenible y protección del medio ambiente. Madrid: Civitas. 2002. p.49-80. p.67 e 68. 
De fato, reconhecer que as ciências e a técnica participam do governo dos homens, conseguinte levar a sério os riscos que desencadeiam e a análise científica que fazem delas, implica reformular o secular pacto social da ciência, baseado no determinismo de uma evolução sem consequências maléficas. $\mathrm{Na}$ ordem jurídica, trata-se de inserir a ciência, a técnica e os seus riscos à hierarquia normativa, para Ihes dar uma operatividade coerente, em vez de regulá-las de forma casual. Dessa inserção, emergirão duas situações distintas: a organização voluntária da sociedade do conhecimento científico e o reconhecimento dos riscos que estão associados a ela. Não obstante, na prática, ambas as situações não se acham vinculadas, o que demonstra a falta de discernimento humano quanto a seus próprios limites ${ }^{61}$.

Deve-se registrar, desde o Direito ambiental, expandido pela sustentabilidade científica, que não se busca defender um pessimismo em relação aos instrumentos de gestão ambiental em sua perspectiva técnica-ecológica, o que se intenta destacar é que o papel da vertente socioeconômica, científica e popular deva ser amplificado no ordenamento jurídico, cujo efeito contribuirá para a avaliação integral dos efeitos "glocalizados" da ação técnica, assim como permitirá às instituições intervenientes se aproximarem de uma gestão jurídica eficiente do meio ambiente.

Em suma, o Direito ambiental vinculado à sustentabilidade trata-se de uma ciência que imponha o uso de técnicas de avaliação e acompanhamento de indicadores ambientais não apenas ecológicos, mas também socioeconômicos, o que virá consolidar três vias de projeção jurídica e científica: a técnico-ecológica, via desenvolvimento das ciências naturais e tecnologias; a técnica-social, por meio da participação pública e conhecimento socioeconômico associado; assim mesmo, haverá a terceira direção, que é a determinante emulsão das anteriores ao promover decisões que venham a influenciar e permitir consolidar a sustentabilidade.

61 HERMITTE, Marie - Angèle. La fundación jurídica de una sociedad de las ciencias y de la técnica a través de las crisis y de los riesgos. p.19. 


\section{CONSIDERAÇÕES FINAIS}

Como se pôde inferir, especialmente por meio de matizações científicas extraídas especialmente por meio da literatura vinculada à filosofia e à história da ciência, da tecnologia, da sustentabilidade e do direito ambiental, que na atualidade, os instrumentos de gestão hoje adotados nas legislações ambientais se condicionam preponderantemente na vertente físico-natural da ciência, que tal e como observado, costuma ser essa perspectiva a saída do ordenamento jurídico com vistas à predição e ao controle dos processos ecológicos; por isso, em várias ocasiões se nomeou esse influxo jurídico rumo às ciências naturais como de técnico-ecológico.

Não obstante, o fator social e econômico, até mesmo o físico-natural, não pode ser prognosticado tão somente por essa lógica de retroalimentação técnica, pois diferente das dinâmicas ecológicas, eles estão estreitamente ligados a critérios subjetivos, coletivos, socialmente imprevisíveis e injustos, próprios e inerentes às relações socioeconômicas. Sendo assim, inspirado em dada sustentabilidade científica, ou Ciência da Sustentabilidade, o Direito ambiental e suas normas jurídicas, respectivamente, mostram-se como a ciência e a técnica social medial, apta a colocar esses distintos pilares, ecológico, social e econômico, para confrontar-se através da participação pública e inserção dos saberes sociais. Para isso, a ciência jurídica procede remodelar seu instrumental e dinamizá-lo segundo a nova ordem científica imposta pela sustentabilidade, para que logo seja adequada a fomentar a avaliação e a gestão do entorno em sua plenitude de fatores ante os impactos, presente e futuro, das técnicas de modificação ambiental.

Por certo, não só o Direito é necessário nesse processo de otimização social, pois se crê que os demais científicos sociais devem contribuir de forma mais decidida para a compreensão das dinâmicas socioecológicas; para isso, deve pôr em marcha suas técnicas, métodos e indicadores de compreensão e análise da realidade; não tentar mimetizar ou subsidiar precipuamente nos parâmetros das ciências naturais, cenário que facilitaria a compreensão dos liames técnicos e jurídicos das possíveis decisões político-administrativas quanto à precaução, à prevenção e à limitação 
dos híbridos riscos e impactos à sustentabilidade. Ou seja, tem-se que uma ação social conjunta, científica e popular, permitirá a aproximação da norma jurídica à autenticidade, à interdisciplinaridade e à hibridez técnica, e ao efetivo interesse público, desencadeando, portanto, um regular reparto dos custos e dos benefícios inerentes às múltiplas modificações ambientais levadas a cabo.

Conseguinte, em um cenário de rendição de contas e governança para sustentabilidade, demanda-se maior objetividade das normas jurídicas ao resguardar os direitos envolvidos, para tanto, exige-se que se projetem posições de controle nos pontos vitais, mais especificamente nos processos de tomada de decisão, avaliação e acompanhamento das ações impactantes; perspectiva normativa que possibilitará uma pertinente compreensão da interação existente entre fatores ecológicos alterados e socioeconômicos afetados; em suma, em consonância com umas normas jurídicas da sustentabilidade.

Enfim, para o Direito ambiental - da sustentabilidade -, o fato de que o efeito da técnica ou tecnologia seja a transformação do entorno demanda uma ciência jurídica cujo instrumental seja capaz de interrogar os atores sociais sobre até que ponto há legitimidade socioecológica de efetuar referidas transformações ambientais; encargo jurídico esse que reflete a função social e científica básica que deve exercer ao mediar a sustentabilidade propugnada para o século XXI.

REFERÊNCIAS

ALENZA GARCÍA, José Francisco. Manual de Derecho ambiental. Pamplona: Universidad Pública de Navarra. 2001.

ALONSOGARCÍA, Enrique.Legislación sectorial de Medio Ambiente. Revista de Administración Pública, Madrid, n.137, p.57-92. mayo-agosto 1995.

BOWLER, Peter J.; MORUS, Iwan Rhys. Panorama general de la ciencia moderna. Traducción Joan Soler. Barcelona: Critica. 2007.

BRASIL. Segunda Turma do Superior Tribunal de Justiça. Recurso Especial $\mathbf{n}^{\circ} \mathbf{1 . 0 9 4 . 8 7 3}$ - SP. Ministros Humberto Martins, Herman Benjamin, Mauro Campbell Marques, Eliana Calmon e Castro Meira. Relator Ministro Humberto Martins. Brasília (DF), 04 de agosto de 2009 (Data do Julgamento). DJ: 17/08/2009. 
BRÜSEKE, Franz Josef. Riesgo y contigencia. In: VARELLA, Marcelo Dias (Org.). Derecho, sociedad y riesgo. La sociedad contemporánea vista a partir de la idea de riesgo: Rede Latinoamericana y europea sobre gobierno de los riesgos. Brasília: UniCEUB, UNITAR, 2007.

BRÜSEKE, Franz Josef. A Modernidade Técnica. Revista Brasileira de Ciências Sociais, São Paulo, v.17, n.49, p.135-144, junho, 2002.

CAMBRA BASSOLS, Jordi de. La teoría crítica y el problema del método en las ciencias sociales. Reis: Revista española de investigaciones sociológicas, Madrid, n.17, p. 53-64. 1982.

CEPAL. Ciencia y tecnología para el desarrollo sostenible. Disponível em: http://repositorio. cepal.org/bitstream/handle/11362/6538/S0316_es.pdf?sequence=1.

CHALMERS, Alan F. La ciencia y cómo se elabora. Traducción de Eulalia Pérez Sedeño. Madrid: Siglo Veintiuno de España, 1992.

CRUZ, Branca Martins da. Responsabilidade civil pelo dano ecológico: alguns problemas. Revista de Direito Ambiental, São Paulo, n. 5, p. 5-41. 1997.

CUTCLIFFE, Stephen H. Ideas, máquinas y valores: Los estudios de Ciencia, Tecnología y Sociedad. Traducción Isabel Chacón Chacón. Barcelona: Anthropos; México: Universidad Nacional Autónoma de México, 2003.

ESTEVE PARDO, José. El componente técnico del Derecho del medio ambiente. Limitaciones y posibilidades de los entes locales. In: ESTEVE PARDO, José (Coord.). Derecho del medio ambiente y Administración Local. Madrid: Civitas. 1996.

ESTEVE PARDO, José. Técnica, riesgo y derecho: tratamiento del riesgo tecnológico en el derecho ambiental. Barcelona: Ariel, 1999.

ESTEVE PARDO, José. El desconcierto del Leviatán: política y derecho ante las incertidumbres de la ciencia. Madrid: Marcial Pons, 2009.

FUNTOWICZ, Silvio O.; RAVETZ, Jerome R. La ciencia posnormal: ciencia con la gente. Barcelona: Icaria, 2000.

GÓMEZHERAS, José María G. El apriori del mundo de la vida:fundamentación fenomenológica de una ética de la ciencia y de la técnica. Barcelona: Anthropos, 1989.

GÓMEZ OREA, Domingo; GÓMEZ VILLARINO, Mauricio. Consultoría e ingeniería ambiental: planes, programas, proyectos, estudios, instrumentos de control ambiental, dirección y ejecución ambiental de obra, gestión ambiental de actividades. Madrid: Mundi-Prensa, 2007. 
HABERMAS, Jürgen. Ciencia y técnica como “ideología”. Traducción Manuel Jiménez Redondo y Manuel Garrido. 5. ed. Madrid: Tecnos, 2007.

HERMITTE, Marie - Angèle. La fundación jurídica de una sociedad de las ciencias y de la técnica a través de las crisis y de los riesgos. In: DIAS VARELLA, Marcelo (Org.). Derecho, Sociedad y riesgo. La sociedad contemporánea vista a partir de la idea de riesgo: Rede latinoamericana y europea sobre gobierno de los riesgos. Brasília: UniCEUB, UNITAR, 2007.

IRIGALBA, Ana Carmen; ETXALEKU, Ana Isabel; ECHAVARREN, José M. La evaluación de impacto ambiental: Recopilación, análisis y punto de vista crítico desde la perspectiva sociológica. In: ALEDO TUR, Antonio; DOMÍNGUEZ GÓMEZ, José Andrés (Directores). Sociología Ambiental. Granada: Grupo Editorial Universitario, 2001.

JERNECK, Anne et al. Structuring sustainability science. Sustainability Science, v. 6, n. 1, p. 69-82. 2011.

JIMÉNEZ HERRERO, Luis M. Desarrollo sostenible: transición hacia la coevolución global. Madrid: Ediciones Pirámide. 2000.

KATES, R. W. et al. Sustainability Science. Science, v. 292, n. 5517, p. 641-642. 2001.

KIM, Joon; OKI, Taikan. Visioneering: an essential framework in sustainability science. Sustainability Science. v. 6, n. 2, p. 247-251, 2011.

KUHN, Thomas S. La Estructura de las revoluciones científicas. México. Fondo de Cultura Económica, 1987.

LEFF, Enrique. Epistemologia Ambiental. 3. ed. Tradução Sandra Valenzuela. São Paulo: Cortez, 2002.

LEMKOW, Louis. Sociología ambiental. Pensamiento socioambiental y ecología social del riesgo. Barcelona: Icaria, 2002.

MARCUSE, Herbert. El hombre unidimensional: ensayo sobre la ideología de la sociedad industrial avanzada. Traducción Antonio Elorza. Barcelona: Ariel, 1984.

MASON, Stephen F. Historia de las ciencias. Barcelona: Zeus, 1966.

MARTÍN MATEO, Ramón. El hombre: una especie en peligro. Madrid: Campomanes Libros, 1993.

MARTÍN MATEO, Ramón. La revolución ambiental pendiente. In: PIÑAR MAÑAS, José Luis (Dir.). Desarrollo Sostenible y protección del medio ambiente. Madrid: Civitas. 2002.

MARTÍN MATEO, Ramón. Manual de Derecho Ambiental. 3. ed. Navarra: Aranzadi, 2003. 
MARTÍN MATEO, Ramón. Tratado de Derecho Ambiental. Tomo IV. Madrid: Edisofer. 2003.

MEDINA GÓMEZ, Manuel. Tecnociencia y cultura. Concepciones, impactos y retos. In: MARQUÉS RODILLA, Cristina (Coord.). El impacto social de la cultura científica y técnica. Madrid: Ministerio de Educación, Cultura y Deporte, Secretaría General Técnica. Subdirección General de Información y Publicaciones. 2004.

MIGLNO,Arnaldo;CRUZ,PauloMárcio;SOARES,JosemarSidinei.Possibilidadesparaatransnacionalidade democrática. Revista Novos Estudos Jurídicos. Itajaí. v. 15, n. 2, p. 193-211. 2010.

MILLER, G. Tyler. Ecología y medio ambiente: introducción a la ciencia ambiental, el desarrollo sustentable y la conciencia de conservación del planeta tierra. Traducción Irma de León Rodríguez y Virgilio González Velázquez. México: Grupo Editorial Iberoamérica, 1994.

MORIN, Edgar. El método. 6. ed. Madrid: Cátedra, 2001.

PARDO BUENDÍA, Mercedes. La evaluación del impacto ambiental y social para el siglo XXI: teorías, procesos, metodología. Madrid: Fundamentos. 2002. p.21.

PAPI, Giuseppe Ugo. Técnica y humanismo. Revista de estudios políticos, Madrid, n.153154, p.29-42. mayo y agosto 1967.

QUERALTÓ, Ramón. Razón científica y razón técnica en el fin de la modernidad. Anuario Filosófico, Navarra, v.27, n.2, p.683-697.1994.

QUINTANILLA, Miguel Ángel. Tecnología: un enfoque filosófico. Madrid: Fundesco, 1989.

REAL FERRER, Gabriel; GLASENAPP, Maikon Cristiano; CRUZ, Paulo Márcio. Sustentabilidade: um novo paradigma para o direito. Revista Novos Estudos Jurídicos. Itajaí. v.19, n.4, p.1433-1464. 2014.

REAL FERRER, Gabriel; GLASENAPP, Maikon Cristiano; CRUZ, Paulo Márcio. Sostenibilidad, transnacionalidad y trasformaciones del derecho. In: SOUZA, M. C. S. A.; GARCIA, D. S. S. (Orgs.). Direito ambiental, transnacionalidade e sustentabilidade. Itajaí: UNIVALI, 2013. Disponível em: http://siaiapp28.univali.br/LstFree.aspx

REAL FERRER, Gabriel; GLASENAPP, Maikon Cristiano; CRUZ, Paulo Márcio. Calidad de vida, medio ambiente, sostenibilidad y ciudadanía ¿Construimos juntos el futuro? Revista Novos Estudos Jurídicos. Itajaí. v.17, n.3, p.310-326. 2012.

REAL FERRER, Gabriel; GLASENAPP, Maikon Cristiano; CRUZ, Paulo Márcio."El Derecho ambiental y el derecho de la sostenibilidad". Palestra proferida em 17 de julho de 2007 
no "Cuarto Programa Regional de Capacitación en Derecho y Políticas Ambientales", em San Salvador, organizado pelo Programa das Nações Unidas para o Meio Ambiente (PNUMA), Ministerio de Medio ambiente y Recursos Naturales de El Salvador, Ministerio de Medio Ambiente de España e Naciones Unidas.

SANMARTÍN, José. Tecnología y futuro humano. Barcelona: Anthropos, 1990.

SANMARTÍN, José; ORTÍ, Ángel. Evaluación de tecnologías. ¿Qué es? ¿En qué contribuye a clarificar las relaciones entre tecnología y sociedad? ¿Cuáles son sus limitaciones? ¿Hay alternativas? In: SANMARTÍN, José et al. (Eds.). Estudios sobre sociedad y tecnología. Barcelona: Anthropos; Leioa (Vizcaya): Universidad del País Vasco, 1992.

SEMPERE, Joaquim; RIECHMANN, Jorge. Sociología y medio ambiente. Madrid: Editorial Síntesis. 2000.

SMITH, Merrit Roe. El determinismo tecnológico en la cultura de Estados Unidos. In: Merrit Roe Smith; Leo Marx (Eds.). Historia y determinismo tecnológico. Traducción Esther Rabasco y Luis Toharia. Madrid: Alianza, 1996.

VILCHES, Amparo; GIL-PÉREZ, Daniel. Ciencia de la Sostenibilidad. Revista Eureka sobre Enseñanza y Divulgación de las Ciencias, v.11, n.3, p.436-438, 2014.

VILCHES, Amparo; GIL-PÉREZ, Daniel. Ciencia de la sostenibilidad: Un nuevo campo de conocimientos al que la química y la educación química están contribuyendo. Educación química, v.24, n.2, p.199-206, 2013

WINNER, Langdon. Tecnología autónoma: la técnica incontrolada como objeto del pensamiento político. Traducción de Ramón Font Segura y Alberto Cardín Garay. Barcelona: Gustavo Gili, 1979.

WYNNE, Brian. Incertidumbre y aprendizaje ambiental: reconcebir la ciencia y la política en un paradigma preventivo. In: GONZÁLEZ GARCÍA, Marta I.; LÓPEZ CEREZO, José A.; LUJÁN, José Luis (Eds.). Ciencia, tecnología y sociedad: lecturas seleccionadas. Traducción Mario Francisco Villa. Barcelona: Ariel, 1997.

ZIMAN, John. Introducción al estudio de las ciencias: los aspectos filosóficos y sociales de la ciencia y la tecnología. Traducción Jordi Bertrán Ferrer. Barcelona: Ariel, 1986.

Recebido em: jun/2015 Aprovado em: jul/2015 